\title{
Amniocentesis in the HIV-infected pregnant woman: Is there still cause for concern in the era of combination antiretroviral therapy?
}

\author{
Nisha Andany BSc MD¹, Michelle Letchumanan BSc², Lise Bondy BSc MD¹, \\ Kellie Murphy MD MSc FRCSC ${ }^{3}$, Mona R Loutfy MD MPH FRCPC ${ }^{1,4}$
}

\begin{abstract}
N Andany, M Letchumanan, L Bondy, K Murphy, MR Loutfy. Amniocentesis in the HIV-infected pregnant woman: Is there still cause for concern in the era of combination antiretroviral therapy? Can J Infect Dis Med Microbiol 2013;24(3):e91-e95.

The current standard of care in Canadian obstetrical practice is to offer pregnant women the opportunity for prenatal investigation to diagnose congenital abnormalities. Prenatal amniocentesis is Canada's most commonly practiced invasive procedure for the diagnosis of chromosomal and single gene disorders. The potential risk of intrapartum HIV transmission during amniocentesis raises several ethical concerns and limits the availability of prenatal genetic testing for HIV-positive pregnant women. Complete virological suppression with antiretroviral therapy may alleviate the risk of mother-to-child transmission during amniocentesis and increase accessibility of this important diagnostic tool in the HIV-positive population. The present report describes a case involving a 32-year-old HIV-positive pregnant woman whose plasma viral load was undetectable on antiretroviral therapy; she underwent successful prenatal amniocentesis without transmission of HIV to her infant.
\end{abstract}

\section{L'amniocentèse chez les femmes enceintes infectées par le VIH : faut-il encore s'inquiéter à l'ère de l'antivirothérapie d'association?}

La norme actuelle des soins dans la pratique obstétricale canadienne consiste à offrir aux femmes enceintes la possibilité d'une évaluation prénatale afin de diagnostiquer des anomalies congénitales. L'amniocentèse prénatale est l'intervention invasive la plus pratiquée au Canada pour diagnostiquer des troubles chromosomiques ou monogéniques. Le risque potentiel de transmission intrapartum du VIH pendant l'amniocentèse soulève plusieurs questions éthiques et limite la disponibilité des tests génétiques prénatals chez les femmes enceintes positives au VIH. La suppression virologique totale grâce à l'antirétrovirothérapie pourrait réduire le risque de transmission entre la mère et l'enfant pendant l'amniocentèse et accroître l'accessibilité à cet important outil diagnostique au sein de la population positive au VIH. Le présent rapport décrit le cas d'une femme enceinte de 32 ans positive au VIH sous antivirothérapie et dont la charge virale plasmatique n'était pas décelable. Elle a subi une amniocentèse prénatale sans transmettre le VIH à son nourrisson.

Key Words: Amniocentesis; Antiretroviral therapy; HIV; Undetectable viral load

$\mathrm{T}$ he goal of equitable HIV management is to provide HIV-positive pregnant women with the same standard of obstetrical care that is available to the general population, including access to prenatal screening and diagnostic procedures. Mid-trimester amniocentesis is the most commonly used invasive procedure during pregnancy for the diagnosis of genetic and chromosomal abnormalities (1). Traditionally, invasive procedures in pregnancy have been contraindicated in HIVpositive women due to concerns that there may be an increased risk of viral transmission to the fetus; this increased risk is believed to be associated with procedure-associated fetal-placental contact and intraamniotic bleeding (2-5). In 2003, the Society of Obstetricians and Gynaecologists of Canada (SOGC) issued guidelines for clinical counselling on prenatal amniocentesis in HIV-positive women; these guidelines recommend that every alternative be exhausted before conducting amniocentesis in this patient population (6). However, the concern regarding increased risk of vertical transmission associated with amniocentesis is based on studies that were conducted before the use of combination antiretroviral therapy (ART) in pregnancy. The availability and effectiveness of combination therapy has had dramatic implications for pregnancy in the HIV-positive population. With a triple ART regimen, the risk of mother-to-child transmission has been reduced from $15 \%$ to $40 \%$ to approximately $1 \%(3,7)$. Consequently, a significantly higher proportion of HIV-infected women are choosing to become pregnant (8), and equitable access to high-quality obstetrical care, including prenatal diagnostic tests, becomes an important consideration. There are data to suggest that mid-trimester amniocentesis, in the era of effective ART, does not result in an increased risk of vertical transmission (9-13). However, the Canadian guidelines have not been updated to reflect these findings and may pose a barrier to optimal prenatal management for the HIV-infected pregnant population. In the present report, we discuss a case involving a 32-year-old HIV-positive woman who successfully underwent prenatal amniocentesis without transmission of the virus to her infant.

\section{CASE PRESENTATION}

A 32-year-old woman of Ugandan descent was diagnosed with HIV in 2003. Method of transmission was heterosexual intercourse and she was diagnosed based on immigration testing. Her baseline CD4 count was 120 cells $/ \mathrm{mm}^{3}$ and viral load (VL) was 53,113 copies $/ \mathrm{mL}$. She was initially started on therapy with abacavir (ABC) (300 mg twice daily), lamivudine (3TC) (150 mg twice daily) and efavirenz (600 mg once daily) in 2003. She was unable to tolerate efavirenz and her antiretroviral regimen was subsequently changed to $\mathrm{ABC} / 3 \mathrm{TC}$ and lopinavir/ ritonavir (LPV/r, Kaletra) (three capsules, $400 \mathrm{mg} / 100 \mathrm{mg}$ twice daily). With this regimen, she achieved and maintained an undetectable VL $(<50$ copies $/ \mathrm{mL})$ and had a CD4 count of approximately 380 cells $/ \mathrm{mm}^{3}$. Her medical history was otherwise significant for malaria in 2002, sickle cell trait and previous hepatitis B virus (HBV)

${ }^{1}$ Department of Medicine; 2 Institute of Health Policy, Management and Evaluation, University of Toronto; ${ }^{3}$ Women's College Research Institute, Women and HIV Research Program; ${ }^{4}$ Department of Obstetrics $\mathcal{E}$ Gynecology, Mount Sinai Hospital, Toronto, Ontario

Correspondence: Dr Mona Loutfy, Women's College Research Institute, Women's College Hospital, 790 Bay Street, Room 736, Toronto, Ontario M5G 2N8. Telephone 416-351-3732 ext 2324, fax 416-351-3746, e-mail mona.loutfy@wchospital.ca 
infection (core antibody positive, surface antigen negative). There was no history of AIDS-defining illness.

The patient had three previous pregnancies (one spontaneous abortion, two therapeutic abortions); she became pregnant in 2008 while on ART (ABC/3TC/LPV/r) and her regimen was continued. At 11 weeks' gestational age, a fetal ultrasound demonstrated a cystic hygroma with nuchal fold measuring $3.4 \mathrm{~mm}$; this can imply a significantly higher risk of chromosomal abnormalities (14). The patient was followed closely by her obstetrician and a repeat ultrasound performed at 15 weeks demonstrated reduction in the size of the hygroma $(2 \mathrm{~mm})$. After discussing the risks and benefits of further diagnostic testing, a prenatal amniocentesis was performed at 16 weeks. Karyotypic and genetic analysis confirmed the absence of any significant chromosomal abnormality, but did establish a diagnosis of sickle cell disease in the fetus. The patient and her partner elected to continue the pregnancy.

At 15 weeks, the patient reported an intolerance to LPV/r, mainly nausea and diarrhea; this resulted in a substitution from $L P R / r$ to saquinavir and ritonavir (500 mg/100 mg twice daily); her ABC/3TC were continued without any adverse effects. Additional medications during the pregnancy included a maternal vitamin (Materna, Pfizer Consumer Healthcare, Canada), calcium, terbinafine hydrochloride and Rho(D) Immune Globulin (Rhogam, Ortho-Chemical Diagnostics, USA). The patient reported regular adherence to treatment. Throughout the pregnancy, her CD4 count was maintained at approximately 380 cells $/ \mathrm{mm}^{3}$ and VL remained undetectable. At 35 weeks' gestational age, the patient developed pre-eclampsia and HELLP syndrome; she underwent Caesarean section with the use of intravenous zidovudine (azidothymidine [AZT]) during the perioperative period. She delivered a healthy female infant. The infant was referred to the Hospital for Sick Children (Toronto, Ontario) for follow up and underwent serial HIV testing as per protocol (HIV DNA polymerase chain reaction testing at zero, one and two months, ELISA at 18 months), all of which were negative. Aside from the diagnosis of sickle cell disease, the child is healthy and has experienced no other medical conditions.

\section{DISCUSSION}

The present report provides a Canadian perspective of an HIV-positive woman who successfully underwent amniocentesis for prenatal diagnosis without vertical transmission. Prenatal mid-trimester amniocentesis is at the forefront of obstetrical practice for the diagnosis of chromosomal and single gene defects. The procedure involves sampling of amniotic fluid via needle puncture of the uterine wall and is traditionally offered to pregnant women who are at higher risk of having a child with a congenital abnormality; this includes women with abnormal ultrasounds or noninvasive screening tests, or those who have a predisposition to congenital abnormalities (advanced maternal age, family history of congenital birth defect, prenatal infection, substance use, etc) (1). Amniocentesis can also be used later in pregnancy for the diagnosis of prenatal infection or to assess fetal lung maturity (15).

There are several risks associated with amniocentesis including spontaneous abortion and fetal demise, premature rupture of membranes, chorioamnionitis, fetal-maternal bleeding and intra-amniotic bleeding $(1,3,4)$. There are concerns that exposure to maternal blood during amniocentesis may increase the risk of intrauterine transmission of several blood-borne viruses, especially if a transplacental approach is used $(3,5)$. The risk of perinatal HBV transmission is highly variable, ranging from $10 \%$ to $15 \%$ in those who are hepatitis $\mathrm{B}$ e antigen ( $\mathrm{HBeAg}$ ) negative to up to $70 \%$ to $90 \%$ in those who are $\mathrm{HBeAg}$ positive $(3,6)$. With prophylaxis, transmission risk can be reduced to $5 \%$ to $15 \%$ (3). Hepatitis B surface antigen has been detected in the amniotic and cord blood of infants with HBVinfected mothers; however, HBV DNA has not been detected, suggesting that the complete virus does not cross the placenta $(16,17)$. There are few studies that have examined HBV transmission with amniocentesis, but available data indicate that in mothers who are $\mathrm{HBeAg}$ negative, the risk is equivalent to those not undergoing amniocentesis $(17,18)$. A positive $\mathrm{HBeAg}$ status can increase this transmission risk up to $30 \%$ (18). The natural rate of hepatitis $\mathrm{C}$ (HCV) vertical transmission ranges from $\leq 1 \%$ in women who are HCV RNA negative, to $5 \%$ in those who are HCV RNA positive; HIV coinfection can further increase the risk up to $20 \%$ (3). There are very little data with respect to HCV transmission during amniocentesis. In one study of $22 \mathrm{HCV}$-infected women (16 HCV RNA positive) who underwent a second-trimester amniocentesis, HCV RNA was detected in the amniotic fluid of one infant but the child subsequently tested negative for infection (19). There were no instances of vertical transmission, but only 10 infants were tested. However, no definitive conclusions can be drawn from these data. For HBV and HCV, the SOGC suggests that the risk of transmission with amniocentesis is low and that these procedures can likely be safely performed; however, HBeAg status of the mother may influence the decision to perform the procedure given the increased risk in those who are HBeAg positive (6).

The vast majority of worldwide pediatric HIV infection occurs perinatally. The risk of vertical HIV transmission in pregnancy ranges from $15 \%$ to $40 \%$ when ART is not used; approximately $30 \%$ occurs in the antenatal period and $70 \%$ occurs in the intrapartum period $(3,7,20)$. HIV has been detected in the amniotic fluid of pregnant women, but this does not appear to occur frequently. In a case report involving an HIV-infected woman who underwent amniocentesis in the third trimester of pregnancy, HIV was isolated via viral culture from the amniotic fluid. This patient was not on ART and no information is available regarding the HIV-status of the infant (21). In a subsequent study of women undergoing amniocentesis during pregnancy $(n=29)$ and those who had amniotic fluid collected at delivery $(n=38)$, HIV RNA was not detected in any of the amniotic fluid samples (13). Eighty-four per cent of women in this study were on ART. Similarly, a study of amniotic fluid from 23 HIV-infected women taken at elective Caesarean section did not show the presence of HIV RNA (20). An examination of 40 HIV-infected women who had amniotic fluid sampled during elective Caesarean section revealed HIV RNA in three samples (7.5\%); in each case, VL in the amniotic fluid was $<100$ copies $/ \mathrm{mL}$, the mother was on ART with a suppressed plasma VL and all three neonates had undetectable plasma VL at birth (22). These data suggest that while HIV RNA may infrequently be present in amniotic fluid, this does not necessarily translate to fetal infection.

Previous studies have suggested higher rates of intrauterine viral transmission when amniocentesis is performed in HIV-positive women $(2,15,23)$. Mandelbrot et al (2) reported data on a cohort of 68 HIV-infected women who underwent invasive procedures during pregnancy between 1985 and 1993; of these 68 procedures, 13 were amniocenteses and 26 were amnioscopy (both considered needling procedures). Only $5.5 \%$ of the total study population received antenatal zidovudine (AZT) and the HIV transmission rate among women who underwent an invasive needling procedure was $36 \%$, compared with $18.5 \%$ in those that did not have any procedure during pregnancy (OR 2.08) (2). Similarly, HIV transmission occurred in six of 15 infants born to HIV-positive mothers who underwent genetic amniocentesis during the third trimester (OR 4.10) (15). Furthermore, in a study involving $196 \mathrm{HIV}$-infected women who were on AZT monotherapy in pregnancy, vertical transmission was associated with any condition or procedure that increased the risk of fetal-maternal bleeding, including amniocentesis (23). These data have prompted clinicians to be cautious about counselling HIVpositive women toward amniocentesis. The SOGC guidelines for the use of amniocentesis in women with HIV, while recognizing that data regarding transmission risk were sparse and that the effect of combination therapy is unknown, suggest that every effort be made to avoid performing amniocentesis in HIV-infected pregnant women (6). 
TABLE 1

Regional guideline recommendations for the use of invasive procedures in pregnancy

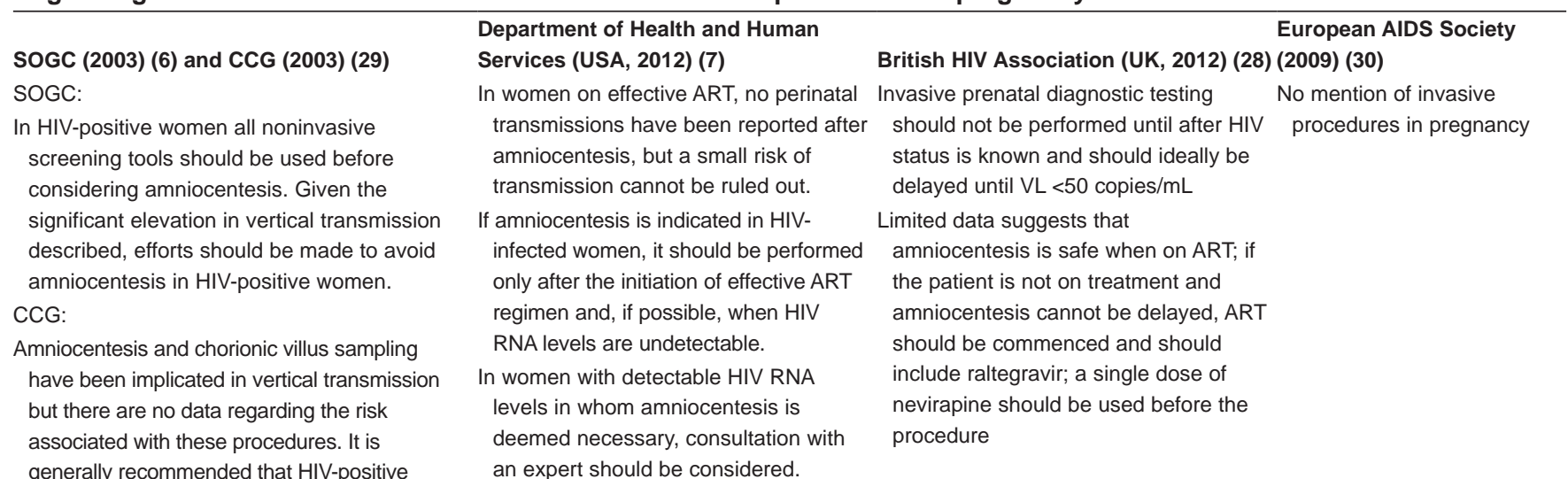
( pregnant women not undergo these procedures unless the benefits outweigh the risks.

ART Antiretroviral therapy; CCG Canadian Consensus Guidelines for the management of HIV positive pregnant women and their offspring; SOGC Society of Obstetricians/Gynecologists of Canada; UK United Kingdom; VL Viral load

It is important to note that the aforementioned studies were conducted before the use of combination therapy. The introduction of ART has had a tremendous impact on HIV-associated morbidity and mortality. With the use of combination therapy, in addition to safe mode of delivery and avoidance of breastfeeding, the risk of motherto-child HIV transmission can now be reduced to approximately $1 \%$ (7). The effectiveness of combination ART in preventing vertical transmission is related to viral suppression; the most important predictor of transmission is maternal VL and women with $\mathrm{VL}<1000$ copies/mL have a minimal risk of transmitting HIV to their infants (24). Antiretroviral agents can also penetrate the amniotic fluid to different degrees. An analysis of six women on ART with amniotic fluid samples collected at delivery demonstrated that nucleoside reverse transcriptase inhibitor levels were higher than maternal concentrations (3TC 14-fold higher, AZT fourfold higher, tenofovir 158 times higher); nevirapine concentration was approximately $47 \%$ lower than maternal blood levels and protease inhibitor (PI) levels were substantially lower than maternal values indicating poor penetration (LPV and ritonavir 96\% lower than maternal levels) (25). The low concentration of PIs in amniotic fluid were also demonstrated in a study of 24 women who received ART in pregnancy; PI concentrations were below the limit of detection in 10 of 16 fluid samples for nelfinavir, one of three samples with indinavir, and four of four samples for ritonavir (26). However, despite variations in amniotic fluid penetration, combination therapy, with or without PIs, continues to substantially reduce the risk of vertical transmission and PI-based regimens are considered to be first line by the United States (US) Department of Health and Human Services for the prevention of mother-to-child transmission (7). The utility of measuring antiretroviral levels in amniotic fluid is unclear and levels were not measured in our patient.

Lower rates of vertical transmission associated with amniocentesis have emerged in the era of effective ART (9-13). In a study involving $366 \mathrm{HIV}$-infected pregnant women, risk of vertical transmission was compared between two groups undergoing amniocentesis: those who underwent amniocentesis before 1997 (group 'a' $[n=11]$ ), and those who underwent amniocentesis after 1997 and just before delivery (group ' $b$ ' $[n=18]$ ). The rate of HIV transmission was $30 \%$ (three of 10) in women who had undergone amniocentesis before 1997 , compared with $16.2 \%$ in those who did not undergo the procedure; of the three cases of transmission, two occurred in women not on therapy and one in a women with a CD4 count $<200$ cells/ $\mathrm{mm}^{3}$ (13). Of all women who underwent amniocentesis after 1997, rates of transmission did not differ from those who did not undergo the procedure (13). A retrospective review of 60 infants born to mothers who underwent amniocentesis in pregnancy ( $84 \%$ on ART) found that the rate of transmission $(3.3 \%)$ was no different from the group who did not undergo amniocentesis (12). Coll et al (11) reported a study involving $116 \mathrm{HIV}$-infected pregnant women in which 10 women underwent amniocentesis. The median gestational age at the time of the procedure was 16.5 weeks and $70 \%$ of women had an undetectable VL; two pregnancies resulted in fetal demise and two women elected for pregnancy termination due to detection of a congenital abnormality. Of the six viable infants, there were no instances of vertical transmission (11). Similarly, Ekoukou et al (10) studied 11 women who underwent amniocentesis during pregnancy while on combination ART. There were two cases of fetal anomaly leading to termination of pregnancy and, of the nine live-born infants, none tested positive for HIV infection (10). Finally, in a study from the French Perinatal Cohort (9), 166 HIV-infected women underwent amniocentesis from 1985 to 2006. At the time of the procedure, median gestational age was 20 weeks and $78.9 \%$ of women were on ART ( $71.8 \%$ on combination therapy). There were 157 live births; the rate of pregnancy termination was higher in the group of women who had amniocentesis performed. The overall rate of transmission was $16.2 \%$. There was a trend toward higher rates of transmission in women not on ART (25\%), as well as in those on AZT monotherapy $(6.1 \%)$ or dual ART $(3.3 \%)$; there was no vertical transmission among the 81 pregnancies in which the mother was being treated with combination ART (9).

Despite the apparent safety of performing amniocentesis in HIVinfected pregnant women in the era of combination of therapy and VL suppression, the Canadian guidelines have not been updated to reflect these findings. This is in contrast to other regional guidelines for the management of HIV in pregnancy (Table 1). The US Department of Health and Human Services "Recommendations for Use of Antiretroviral Drugs in Pregnant HIV-Infected Women for Maternal Health and Interventions to Reduce Perinatal HIV Transmission in the United States" were modified in 2010. The 2009 guidelines noted that amniocentesis had been found to increase risk of vertical transmission in some studies, but did recognize that these studies had not been performed in the era of potent ART (27). In the 2010 to 2012 guidelines, these recommendations were updated to recognize the lower risk of transmission with combination therapy (7); they caution that while an increased risk of transmission cannot be completely ruled out, amniocentesis can be performed, when indicated, after the initiation of effective ART and ideally once VL is suppressed. If the VL is detectable, expert consultation is suggested. The British HIV 
Association has issued perinatal guidelines since 2001; while the language has been updated with each successive version, all of them maintain that if amniocentesis is indicated, the transplacental approach should be avoided and periprocedural ART may be required (28).

There are no available data to direct Canadian guidelines with regard to performing amniocentesis when the test is indicated, including information on whether rates of amniocentesis in HIV-infected pregnant women in Canada have increased with the use of combination therapy. Studies from Europe indicate that rates of amniocentesis are increasing in the HIV-infected population. One Italian study noted that rates of amniocentesis increased from 4\% in 1997 to $14 \%$ in 2003 (12). Data from the French Perinatal cohort similarly demonstrated that rates increased from $0.8 \%$ before 1994 to $4.7 \%$ in 2005 (9). An additional French study conducted between 2001 and 2006 reported that $32.4 \%$ of women with an indication for amniocentesis underwent the procedure. The procedure was only performed in women on triple ART with a suppressed VL and CD4 count $>200$ cells $/ \mathrm{mm}^{3}$ and there was no reported viral transmission (10).

Combination ART has completely revolutionized HIV medicine and has decreased the risk of mother-to-child transmission to $\leq 1 \%$. Consequently, HIV-infected women can have successful pregnancies

\section{REFERENCES}

1. Wilson RD, Langlois S, Johnson J. Mid-trimester amniocentesis fetal loss rate. J Obstet Gynaecol Can 2007;29:586-90.

2. Mandelbrot L, Mayaux MJ, Bongain A, et al. Obstetric factors and mother-to-child transmission of human immunodeficiency virus type 1: The French Perinatal Cohorts. Am J Obstet Gynecol 1996;175:661-7.

3. Lopez M, Coll O. Chronic viral infections and invasive procedures: Risk of vertical transmission and current recommendations. Fetal Diagn Ther 2010;28:1-8.

4. Dugoff L, Hobbins JC. Invasive procedures to evaluate the fetus. Clin Obstet Gynecol 2002;45:1039-53.

5. Giorlandino C, Gambuzza G, D'Alessio P, Santoro ML, Gentili P, Vizzone A. Blood contamination of amniotic fluid after amniocentesis in relation to placental location. Prenat Diagn 1996;16:180-2.

6. Davies G, Wilson RD. Amniocentesis and women with hepatitis B, hepatitis $\mathrm{C}$ or human immunodeficiency virus. SOGC Clinical Practice Guidelines. J Obstet Gynaecol Can 2003;25:145-8.

7. Panel on Treatment of HIV-Infected Pregnant Women and Prevention of Perinatal Transmission. Recommendations for the Use of Antiretroviral Drugs in Pregnant HIV-1-Infected Women for Maternal Health and Interventions to Reduce Perinatal HIV Transmission in the United States. <htpp://aidsinfo.nih.gov/ contentfiles/lvguidelines/PerinatalGL.pdf > (Accessed October 2, 2012).

8. Loutfy MR, Hart TA, Mohammed SS, et al. Fertility desires and intentions of HIV-positive women of reproductive age in Ontario, Canada: A cross-sectional study. PLoS One 2009;4:e7925.

9. Mandelbrot L, Jasseron C, Ekoukou D, Batallan A, Bongain A, Pannier E. Amniocentesis and mother-to-child human immunodeficiency virus in the Agence Nationale de Recherches sur le SIDA et les Hepatites Virales French Perinatal Cohort. Am J Obstet Gynceol 2009;200:160e1-e9.

10. Ekoukou D, Khuong-Josses MA, Ghibaudo N, Mechali D, Rotten D. Amniocentesis in pregnant HIV-infected patients; absence of mother-to-child viral transmission in a series of selected patients. Eur J Obstet Gynecol Reprod Biol 2008;140:212-7.

11. Coll O, Suy A, Hernandez S, et al. Prenatal diagnosis in human immunodeficiency virus-infected women: A new screening program for chromosomal anomalies. Am J Obstet Gynecol 2006;194:192-8.

12. Somigliana E, Bucceri AM, Tibaldi C, et al. Early invasive diagnostic techniques in pregnant women who are infected with the HIV: A multicenter case series. Am J Obstet Gynecol 2005; 193:437-44.

13. Maiques V, Garcia-Tejedor A, Perales A, Cordoba J, Esteban RJ. HIV detection in amniotic fluid samples; amniocentesis can be performed in HIV pregnant women? Eur J Obstet Gynecol Reprod Biol 2003;108:137-41. and more of them are choosing to become pregnant. It is important that HIV-positive women have access to the same standard of antenatal care as the general population. While noninvasive screening methods, such as integrated prenatal screening and ultrasounds, can provide a wealth of information, some women will have indications for invasive diagnostic tests due to abnormal test results or predispositions to genetic abnormalities. Mid-trimester amniocentesis is the most common prenatal invasive diagnostic procedure and available information indicates that the procedure can be performed safely without an increased risk of transmission in women with HIV. US and British guidelines have recognized this finding and suggest that after all noninvasive methods have been exhausted, amniocentesis may be conducted in women on combination therapy with a suppressed VL as long as the transplacental approach is avoided. However, barriers to accessing this service in Canada are rooted in evidence published during the pre-ART era. It will be important to consider these issues surrounding amniocentesis when the Canadian HIV pregnancy guidelines are updated.

CONFLICT OF INTEREST: The authors declare that no competing interests exist. No financial support was required for the preparation of this manuscript.

14. Descamps $\mathrm{PH}$, Jourdain O, Paillet $\mathrm{CH}$, et al. Etiology, prognosis and management of nuchal cystic hygroma: 25 new cases and literature review. Eur J Obstet Gynecol Reprod Biol 1997;71:3-10.

15. Tess BH, Rodriguez LC, Newell ML, Dunn DT, Lago TD; the Sao Paulo Collaborative Study for Vertical Transmission of HIV-1. Breastfeeding, genetic, obstetric and other risk factors associated with mother-to-child transmission of HIV-1 in Sao Paulo State, Brazil. AIDS 1998;12:513-20.

16. Towers CV, Asrat T, Rumney P. The presence of hepatitis B surface antigen and deoxyribonucleic acid in amniotic fluid and cord blood. Am J Obstet Gynecol 2001;184:1514-20.

17. Elefsiniotis IS, Papadakis M, Vlahos G, Daskalakis G, Saroglou G, Antsaklis A. Clinical significance of hepatitis B surface antigen in cord blood of hepatitis B e-antigen-negative chronic hepatitis B-infected mothers. Intervirology 2009;52:132-4.

18. Ko TM, Tseng LH, Chang MH, et al. Amniocentesis in mothers who are hepatitis $\mathrm{B}$ virus carriers does not expose the infant to an increased risk of hepatitis B virus infection. Arch Gynecol Obstet 1994;255:25-30.

19. Delamare C, Carbonne B, Heim N, et al. Detection of hepatitis C virus RNA (HCV RNA) in amniotic fluid: A prospective study. J Hepatol 1999;31:416-20.

20. Mohlala BKF, Tucker TJ, Besser MJ, et al. Investigation of HIV in amniotic fluid from HIV-infected pregnant women at full term. J Infect Dis 2005;192:488-91.

21. Mundy DC, Schinazi RF, Gerber AR, Nahmias AJ, Randall Jr HW. Human immunodeficiency virus isolated from amniotic fluid. Lancet 1987;2:459-60.

22. Lobato AC, Aguiar RA, Aleixo AW, et al. HIV-1 RNA detection in the amniotic fluid of HIV-infected pregnant women. Mem Inst Oswaldo Cruz 2010;105:720-1.

23. Shapiro DE, Sperling RS, Mandelbrot L, Britto P, Cunningham BE; for the Pediatric AIDS Clinical Trials Group Protocol 076 Study Group. Risk factors for perinatal human immunodeficiency virus transmission in patients receiving zidovudine prophylaxis. Obstet Gynecol 1999;94:897-908.

24. Ioannidis JP, Abrams EJ, Ammann A, et al. Perinatal transmission of human immunodeficiency virus type 1 by pregnant women with RNA virus loads $<1000$ copies/mL. J Infect Dis 2001;183:539-45.

25. Yeh RF, Rezk NL, Kashuba ADM, et al. Genital tract, cord blood and amniotic fluid exposures of seven antiretroviral drugs during and after pregnancy in human immunodeficiency virus type 1 -infected women. Antimicrob Agents Chemother 2009;53:2367-74.

26. Chappuy H, Treluyer JM, Rey E, et al. Maternal-fetal transfer and amniotic fluid accumulation of protease inhibitors in pregnant women who are infected with human immunodeficiency virus. Am J Obstet Gynecol 2004;191:558-62. 
27. Perinatal HIV Guidelines Working Group. Public Health Service Task Force Recommendations for the Use of Antiretroviral Drugs in Pregnant HIV-Infected Women for Maternal Health and

Interventions to Reduce Perinatal HIV Transmission in the United States. April 29, 2009; pp1-90. <http://aidsinfo.nih.gov/

ContentFiles/PerinatalGL.pdf> (Accessed February 20, 2013).

28. Taylor GP, Clayden P, Dhar J, Gandhi K, Gilleece Y, Harding K.

The British HIV Association guidelines for the management of HIV infection in pregnant women 2012. HIV Medicine

2012;13(Suppl 2):87-157.
29. Burdge DR, Money DM, Forbes JC, et al. Canadian consensus guidelines for the management of pregnant HIV-positive women and their offspring. Can Med Assoc J 2003;168:1683-8.

30. European AIDS Clinical Society. (2011). European Guidelines for the Treatment of HIV-Infected Adults in Europe.

$<$ www.europeanaidsclinicalsociety.org/images/stories/EACS-Pdf/ EACSGuidelines-v6.0-English.pdf>

(Accessed August 15, 2012). 


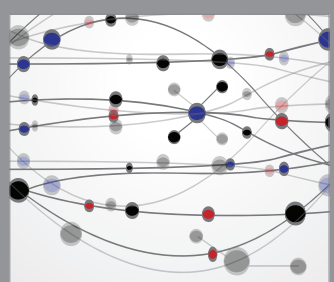

The Scientific World Journal
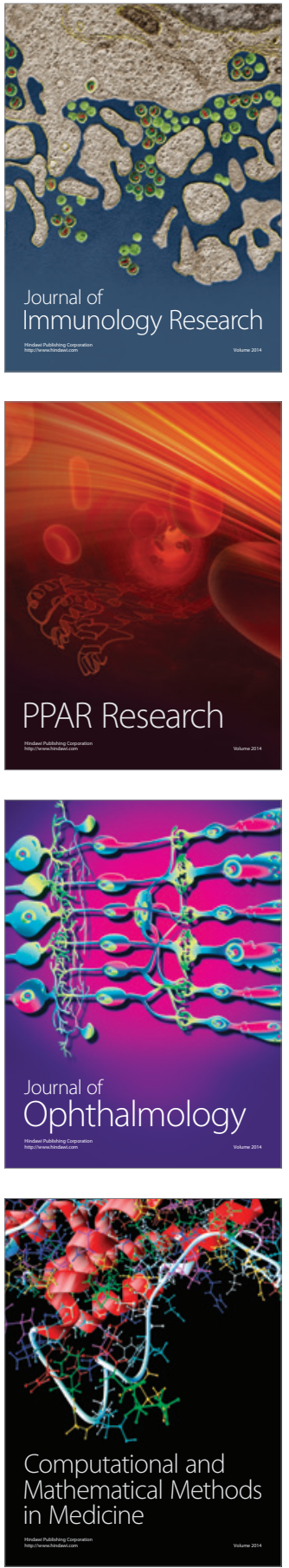

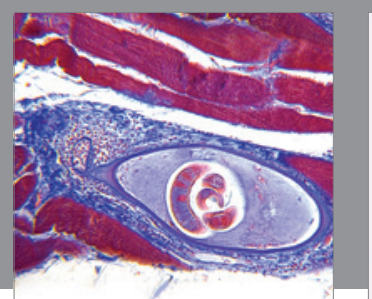

Gastroenterology Research and Practice

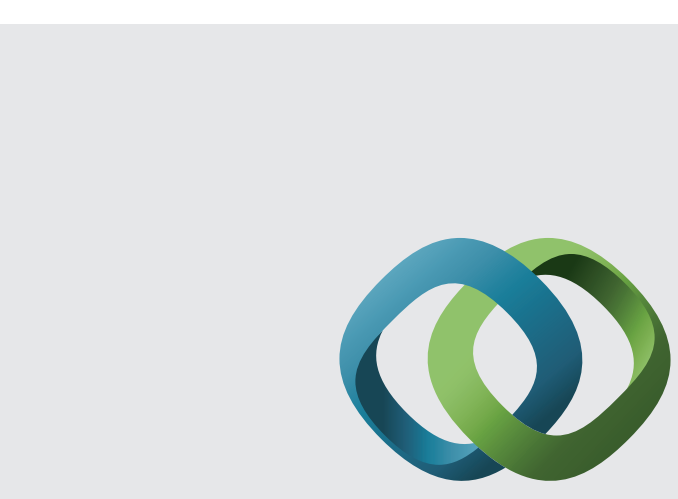

\section{Hindawi}

Submit your manuscripts at

http://www.hindawi.com
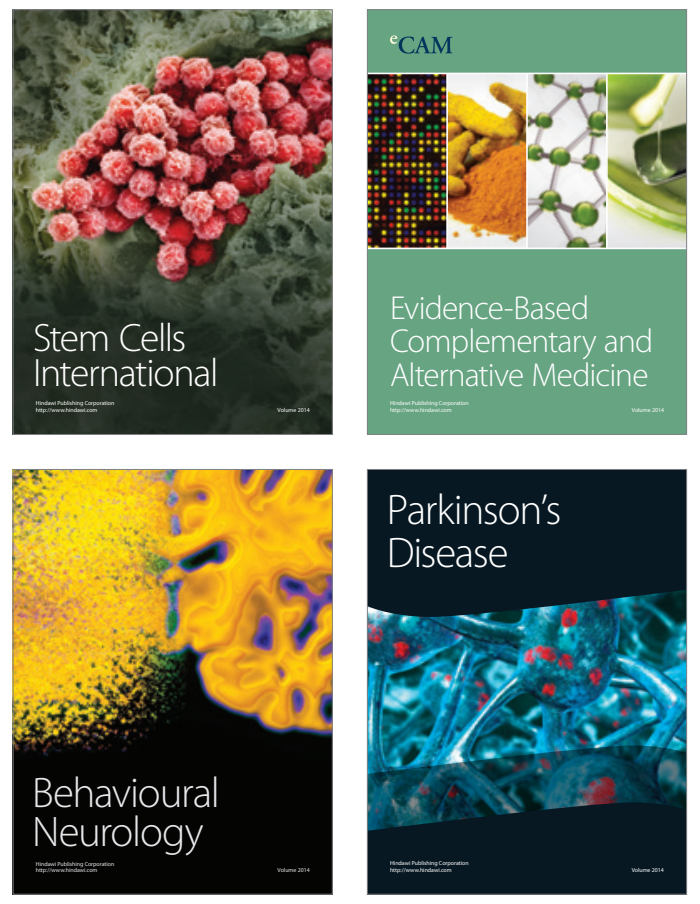
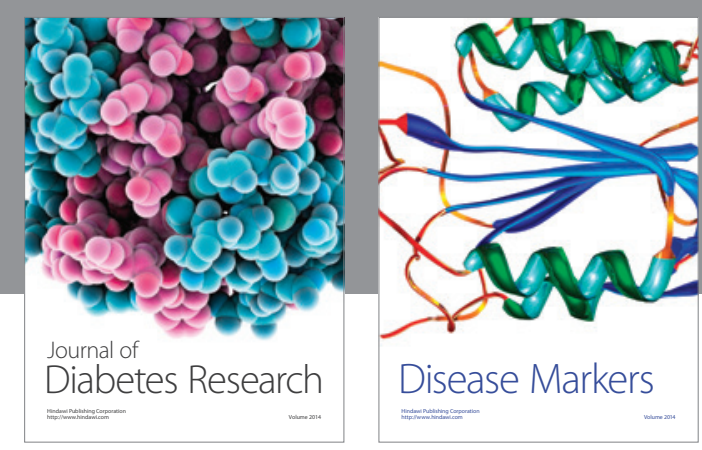

Disease Markers
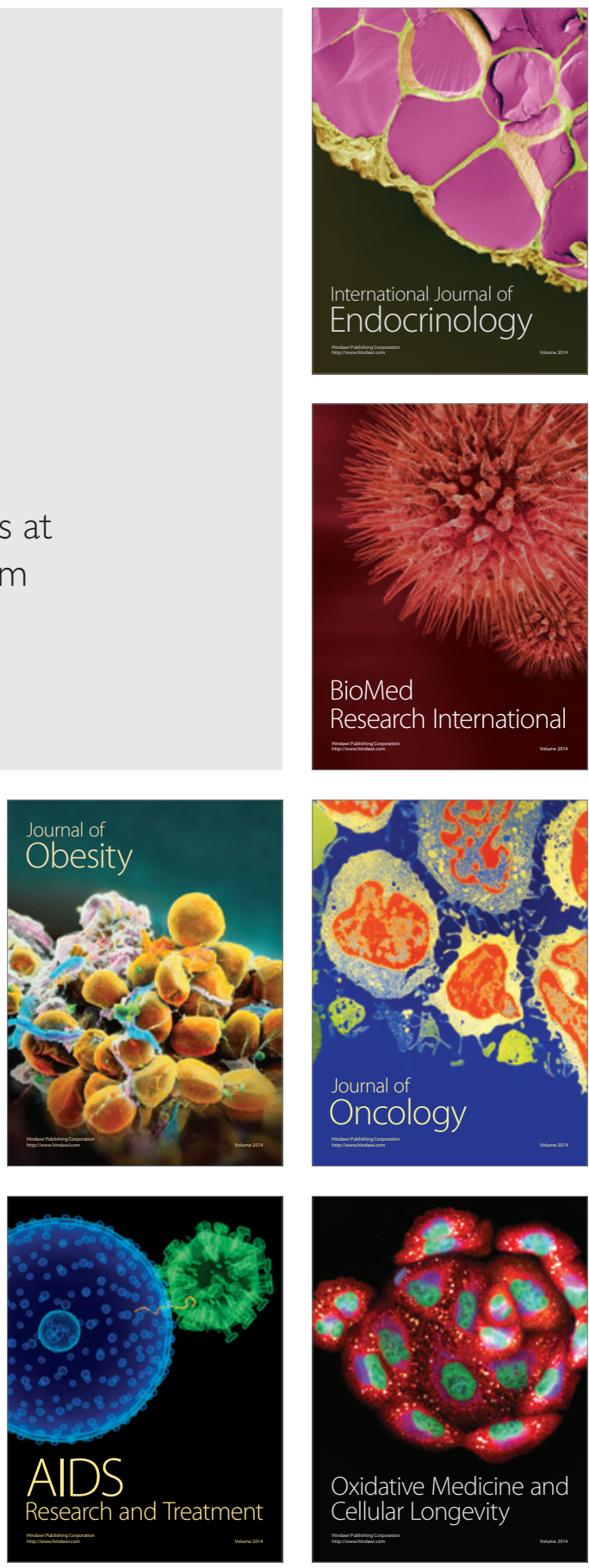